\title{
DESENVOLVIMENTO INICIAL DE MUDAS ENXERTADAS E DE ESTACAS DE CARAMBOLEIRA ${ }^{1}$
}

\author{
DÉBORA COSTA BASTOS², JOÃO ALEXIO SCARPARE FILHO, RAFAEL PIO ${ }^{4}$, MARÍLIA NEUBERN LIBARDI ${ }^{5}$, \\ LUIS FELIPE PAES DE ALMEIDA ${ }^{5}$
}

\begin{abstract}
RESUMO - Na fruticultura atual, é importante a busca de métodos de propagação que reduzam o tempo para o início da produção. Nesse sentido, o estudo de diferentes métodos de propagação torna-se essencial. Para comparar esses dois métodos, desenvolveu-se este estudo com o objetivo de avaliar o efeito de diferentes métodos de propagação e épocas de crescimento sobre o desenvolvimento inicial de mudas de caramboleira. $\mathrm{O}$ delineamento utilizado foi inteiramente casualizado, em esquema de parcela subdividida, com sete repetições e sete plantas por parcela. As parcelas constituíram-se de mudas enxertadas e mudas de estacas e a época de coleta (outono, primavera, verão e inverno), a subparcela, sendo avaliados a cada quatro meses, a altura das plantas e o diâmetro do caule. Os resultados observados na pesquisa permitem concluir que: mudas de caramboleira obtidas através da enxertia apresentam maior taxa de crescimento e, conseqüentemente, maior vigor. Entretanto, as mudas obtidas por estaquia apresentam produção precoce de frutos.
\end{abstract}

Termos para indexação: Averrhoa carambola, estaquia, enxertia e produção de mudas.

\section{EARLY DEVELOPMENT OF STAR FRUIT SCION BY GRAFTING AND CUTTINGS}

ABSTRACT - In the present fruit culture, the search for cropping methods for reduction of production time is important. In this sense, the use of different methods of propagation is essential. To compare those two methods, this study was developed with the objective of evaluate the effect of different methods of propagation and growth seasons on the early development of star fruit scion. The experimental design was completely randomized, in a subdivided parcel scheme, with seven replicates and seven plants each plot. The plots were constituted of grafting and cutting scions and the collection time (autumn, spring, summer and winter) the sub portion, being appraised every four months, the height of the plants and the diameter of the stem. It was concluded that the grafted scions presented larger growth rates in height, and consequently, higher vigor, however, the scion from cuttings presents more precocious production of fruits.

Index terms: Averrhoa carambola, cutting, grafting, and scion production.

A caramboleira é espécie tropical exótica, com crescente expressão econômica cultivada em todo o território nacional, excetuando-se em regiões com baixas temperaturas, e o Brasil está entre os principais produtores mundiais, com produção estimada de 3.000 toneladas/ano (Bastos, 2002). Em 2003, o volume de carambola comercializado pela Ceagesp foi em torno de 2.000 toneladas. Atualmente, o Estado de São Paulo destaca-se como principal produtor, com cerca de $68 \%$ da produção nacional concentrada nos municípios de Mirandópolis, Campinas, Taquaritinga e Lins, responsáveis pela produção (Bastos, 2004).

As pesquisas visando à produção de mudas dessa frutífera são escassas, ao passo que, em outras espécies frutíferas tradicionais, a propagação é um método amplamente difundido, utilizado por viveiristas e produtores de frutas. Em função disso, grande parte do plantio da caramboleira existente é proveniente de sementes, o qual deve ser utilizado somente na formação do porta-enxerto (Bastos \& Scarpare Filho, 2003). Normalmente, mudas obtidas por estaquia são mais precoces do que as mudas obtidas por enxertia (Sauco et al., 1993; Donadio et al., 2001). Plantas com características juvenis não têm capacidade de florescer e tendem a ser extremamente vigorosas; entretanto, plantas adultas, ou mudas provenientes de estacas são caracterizadas pela floração e frutificação, e baixo vigor (Hartmann et al., 2002).

Este trabalho foi realizado com o objetivo de comparar os diferentes métodos de propagação e avaliar os efeitos desses métodos e épocas sobre o desenvolvimento inicial de mudas de caramboleira.

O experimento foi realizado na área de produção de mudas do Departamento de Produção Vegetal da ESALQ/USP, Piracicaba-SP. Foram obtidas 49 mudas através da estaquia, retiradas de ramos herbáceos de plantas-matrizes com 5 anos, da cultivar B-10, e 49 mudas obtidas por enxertia. As estacas foram padronizadas com um par de folhas e $15 \mathrm{~cm}$ de comprimento, sendo acondicionadas em bandejas contendo vermiculita média, sem uso de regulador de crescimento, permanecendo sob nebulização intermitente durante 70 dias (Bastos \& Scarpare, 2003). Após o enraizamento, foram transplantadas para recipientes de polietileno preto $(20 \times 25 \times 20 \mathrm{~cm})$ contendo uma mistura de solo de barranco, areia lavada de rio e matéria orgânica (esterco de curral curtido) na proporção volumétrica $(3: 1: 1)$. Para a obtenção dos porta-enxertos, sementes provenientes de frutos da cultivar Arkin foram colocadas em bandejas de poliestireno contendo plantamax como substrato para germinação e desenvolvimento. A germinação das sementes ocorreu no período de três a quatro semanas decorrentes da semeadura. As mudas foram transplantadas para recipientes de polietileno preto $(20 \mathrm{x}$ $25 \times 20 \mathrm{~cm}$ ), contendo uma mistura de solo de barranco, areia lavada de rio e matéria orgânica (esterco de curral curtido) na proporção volumétrica (3:1:1). A enxertia foi realizada 6 meses após a semeadura. Para a realização da enxertia (garfagem em fenda cheia), os porta-enxertos apresentaram diâmetro entre 0,6 e 1,2 cm, utilizando-se de garfos (copa) da mesma espessura (Meletti, 2000). A cultivar utilizada como portaenxerto foi a Arkin e, como copa, a B-10. As mudas obtidas de enxertia e de estacas permaneceram em câmara de nebulização, para a aclimatação por uma semana, sendo posteriormente levadas para o ripado coberto por sombrite com $50 \%$ de interceptação de luz, efetuando-se irrigações diárias.

O delineamento utilizado foi o inteiramente casualizado, em esquema de parcela subdividida, com 7 repetições de 7 plantas cada. As parcelas constituíram-se de mudas enxertadas e mudas de estacas, representando o tratamento principal e a época de coleta (outono, primavera, verão e inverno) a subparcela, representado o tratamento secundário. Foram avaliados a cada quatro meses, a altura das plantas (medindo a partir do colo) e o diâmetro do caule (cinco $\mathrm{cm}$ acima do colo para mudas de estacas e cinco $\mathrm{cm}$ acima da região da enxertia para

\footnotetext{
${ }^{1}$ (Trabalho 198/2004). Recebido: 21/12/2004. Aceito para publicação: 13/07/2005. Parte da tese do primeiro autor. Apoio financeiro Fapesp.

${ }^{2}$ Eng $^{\circ}$. Agrônoma, M.Sc., Doutoranda em Fitotecnia, Depto. de Produção Vegetal, ESALQ/USP. Av. Pádua Dias, 11 C.P. 09, 13418-900, Piracicaba-SP. Autora para correspondência: dcbastos@esalq.usp.br

${ }^{3}$ Eng $^{\mathrm{o}}$. Agrônomo, D.Sc., Professor do Depto. de Produção Vegetal, ESALQ/USP, Piracicaba-SP.

${ }^{4}$ Eng $^{\circ}$. Agrônomo, D.Sc., PqC. Centro APTA Frutas, IAC. Jundiaí-SP.

${ }^{5}$ Graduando (a) em Engenharia Agronômica, ESALQ/USP, Piracicaba-SP.
} 
TABELA 1 - Médias da altura das plantas $(\mathrm{cm})$ e diâmetro do caule $(\mathrm{mm})$ em função de diferentes épocas de crescimento e tipos de mudas de caramboleira. ESALQ/USP, Piracicaba-SP. 2004.

\begin{tabular}{|c|c|c|c|c|}
\hline \multirow[b]{2}{*}{ Épocas de crescimento } & \multicolumn{4}{|c|}{ Tipos de Mudas" } \\
\hline & \multicolumn{2}{|c|}{ Altura das Plantas } & \multicolumn{2}{|c|}{ Diâmetro do caule } \\
\hline Primavera & $10,65 \mathrm{Ac}$ & $14,61 \mathrm{Ad}$ & $3,12 \mathrm{Bc}$ & $6,42 \mathrm{Ab}$ \\
\hline Outono & $37,42 \mathrm{Ba}$ & $64,31 \mathrm{Ab}$ & $6,25 \mathrm{Aa}$ & $6,97 \mathrm{Aab}$ \\
\hline Inverno & $37,42 \mathrm{Ba}$ & $72,68 \mathrm{Aa}$ & $6,47 \mathrm{Aa}$ & $7,26 \mathrm{Aa}$ \\
\hline cv (\%) Parcela & \multicolumn{2}{|c|}{15,20} & \multicolumn{2}{|c|}{10,99} \\
\hline cv (\%) Subparcela & \multicolumn{2}{|c|}{13,02} & \multicolumn{2}{|c|}{8,75} \\
\hline
\end{tabular}

* Médias seguidas da mesma letra, maiúscula na linha e minúscula na coluna, não diferem estatisticamente entre si, pelo Teste de Tukey, a 5\% de probabilidade.

mudas enxertadas), durante o período de 12 meses. Os dados foram submetidos à análise de variância e as médias ao teste Scott-Knott (1974), ao nível de 1\% de probabilidade (Gomes, 2000). As análises foram realizadas pelo programa computacional Sistema para Análise de Variância - SISVAR (Ferreira, 2000).

Comparando-se a taxa de crescimento em altura das mudas obtidas por estacas $(37,42 \mathrm{~cm})$ e mudas enxertadas $(72,68 \mathrm{~cm})$, pode-se observar que as mudas enxertadas apresentaram um maior desenvolvimento em relação às mudas oriundas de estacas em todas as épocas avaliadas. Esse fato está diretamente relacionado ao vigor da planta, mostrando que as mudas enxertadas tendem a ser mais vigorosas do que as provenientes de estacas (Tabela 1).

De maneira semelhante, analisando-se o diâmetro do caule nos dois tipos de mudas, foi observado maior crescimento e desenvolvimento das mudas enxertadas $(7,26 \mathrm{~mm})$ em relação às mudas de estacas $(6,47$ $\mathrm{mm})$. Esse fato está diretamente relacionado com a altura da planta discutida anteriormente e também ao maior vigor apresentado pelas mudas enxertadas. Entretanto, resultados contrários foram observados por Pacheco et al. (2003), em estudos comparativos entre clones de cacaueiro propagados por enxertia e estaquia, onde as plantas provenientes da estaquia tiveram maior crescimento em altura e diâmetro do que as plantas propagadas por enxertia. Mayer \& Pereira (2004), estudando o crescimento e o desenvolvimento de mudas de umezeiro e pessegueiro provenientes da estaquia, observaram diferenças quanto ao desenvolvimento em altura e diâmetro apresentado pelas plantas. As mudas de umezeiro apresentaram maior taxa de crescimento em altura em relação às mudas de pessegueiro. Entretanto, as mudas de pessegueiro apresentaram maior diâmetro, o que define maior porcentagem de porta-enxertos aptos à realização da enxertia.

Observa-se que houve maior crescimento e desenvolvimento das mudas em altura e diâmetro, tanto as enxertadas como as de estacas, nas mudas produzidas na época do inverno, cujo crescimento ocorreu durante o verão. Essa época favorece o crescimento e o desenvolvimento das plantas, devido às altas temperaturas e elevada umidade, fatores essenciais para que as plantas tropicais, como é o caso da caramboleira, tenham boa atividade fisiológica. Durante esse período, observou-se intenso florescimento e sucessiva produção de frutos nas mudas de estacas, sendo que $30 \%$ floresceram e frutificaram pelo menos uma vez, produzindo em média de dois a três frutos por planta. Esses dados podem mostrar que as mudas provenientes de estacas são mais precoces na produção de frutos quando comparadas com as mudas de pé-franco e enxertadas, que, segundo Donadio et al. (2001), levam em média de dois a três anos para entrarem em produção. Dessa forma, há uma redução de até 2 anos no tempo em que a planta leva para entrar em produção. Por outro lado, nas mudas enxertadas, não houve florescimento e produção de frutos em nenhuma das mudas avaliadas durante o período analisado. Esses resultados estão de acordo com os encontrados na literatura para carambola, citados por Sauco et al. (1993) e Donadio et al. (2001), comprovando a teoria de que mudas provenientes da estaquia geralmente são mais precoces do que as provenientes da enxertia.

$\mathrm{O}$ fato de as mudas de estacas serem mais precoces do que as mudas enxertadas, é devido à interação que ocorre entre porta-enxerto e enxerto. Sabe-se que, em mudas enxertadas, ocorrem significativas interações entre o porta-enxerto e o enxerto. Dos efeitos, ou das interações entre porta-enxerto e enxerto, o mais pronunciado ou o mais evidente é o resultante na alteração do vigor do enxerto. $O$ vigor da nova planta pode ser alterado para mais ou para menos, de acordo com as características do porta-enxerto. Quando da utilização de portaenxertos ananicantes, o vigor da copa diminui (Hartmann et al., 2002). Porém, no caso em estudo, foram utilizados porta-enxertos originários de sementes, ou seja, plantas juvenis. A juvenilidade pode ser definida como o período de crescimento onde o meristema apical não responde aos estímulos internos e externos para iniciação de flores. Nas plantas originárias de sementes, é estabelecido um forte gradiente de juvenilidade. Os tecidos do colo da planta mantêm características juvenis que vão diminuindo à medida que as plantas crescem (Zimmerman, 1972; Hackett, 1983).Embora teoricamente as plantas propagadas por estaquia e por enxertia não provoquem o rejuvenescimento dos tecidos, foi observado que, em plantas enxertadas, mesmo utilizando partes de tecidos adultos no caso da caramboleira, a planta resultante da enxertia mostrou revigoramento pronunciado e inabilidade para florescimento. Essas características não foram apresentadas pelas mudas provenientes de estacas. A juvenilidade está diretamente relacionada com o vigor da planta. A transição da fase juvenil para a fase adulta tem sido referida como a fase de mudança na idade ontogenética ou do meristema. Existem mudanças progressivas nas características morfológicas e de desenvolvimento como forma da folha, padrão de ramos, crescimento de brotações, vigor e habilidade para formar raízes e gemas adventícias (Davis \& Haissig, 1994).

De acordo com os resultados observados nesse estudo da caramboleira, as mudas enxertadas apresentam características juvenis, por serem provenientes de sementes (porta-enxertos), enquanto as mudas originadas por estacas se apresentam com características adultas. Resultados semelhantes foram observados por Hartmann et al. (2002) em maçã e eucalipto, onde a habilidade das estacas para formar raízes diminui com o aumento da idade das plantas provenientes de sementes. Algumas espécies de orquídeas originadas a partir de sementes requerem de 5 a 10 anos após o desenvolvimento para iniciarem o florescimento. Entretanto, quando se utilizada de material propagativo adulto ou maduro, as plantas florescem anualmente e entram em produção (Davis \& Haissig, 1994). Pode-se afirmar que, embora as mudas enxertadas tenham tecidos maduros em sua constituição (parte enxertada) retirados de ramos adultos da planta, elas possuem tecidos com características juvenis (porta-enxerto) por serem provenientes de sementes. No caso específico das mudas de carambola, as características juvenis do porta-enxerto influenciaram no desenvolvimento da muda formada a partir da enxertia, fazendo com que a muda tivesse alto vigor, com elevadas taxas de crescimento em altura, diâmetro do caule, massas frescas e secas da parte aérea e da raiz em relação às mudas provenientes de estacas.Em contrapartida, as mudas de estacas possuem características adultas, porém são menos vigorosas, apresentando precoce produção de frutos.

Como conclusão, pode-se observar que mudas de caramboleira obtidas através da enxertia apresentam maiores taxas de crescimento e 
conseqüentemente maior vigor. Entretanto, mudas obtidas por estaquia são mais precoces.

\section{REFERÊNCIAS}

BASTOS, D.C. Efeito da época de coleta, estádio do ramo e do tratamento com IBA no enraizamento de estacas de caramboleira (Averrhoa carambola L.). 2002. 75f. Dissertação (Mestrado em Agronomia) Faculdade de Ciências Agrárias e Veterinárias, Universidade Estadual Paulista, Jaboticabal, 2002.

BASTOS, D.C.; SCARPARE FILHO, J.A. Estiolamento, ferimento e uso de IBA no enraizamento de estacas herbáceas de caramboleira (Averrhoa carambola L.). In: ANNUAL MEETING OF THE INTERAMERICAN SOCIETY FOR TROPICAL HORTICULTURE, 49., 2003, Fortaleza. Resumos... Fortaleza: Embrapa Agroindústria Tropical, 2003.p. 92.

BASTOS, D.C.; MARTINS, A.B.G.; SCALOPPI JUNIOR, E.J.; SARZI, I.; FATINANSI, J.C. Influência do ácido indolbutírico no enraizamento de estacas apicais e basais de caramboleira (Averrhoa carambola L.) sob condições de nebulização intermitente. Revista Brasileira de Fruticultura, Jaboticabal, v.26, n.2, p.284-286, 2004.

DAVIS, T.D.; HAISSIG, B.E. Biology of adventitious root formation. New York: Plenum Press, 1994. p.37-52.

DONADIO, L.C.; SILVA, J.A.A.; ARAÚJO, P.R.S.; PRADO, R.M. Caramboleira (Averrhoa carambola L.). Jaboticabal: Sociedade Brasileira de Fruticultura, 2001. 81p. (Série Frutas Potenciais).

FERREIRA, D. F. Análise estatística por meio do SISVAR (Sistema para Análise de Variância) para Windows versão 4.0. In: REUNIÃO ANUAL DA REGIÃO BRASILEIRA DA SOCIEDADE
INTERNACIONAL DE BIOMETRIA, 45., 2000, São Carlos. Anais... São Carlos: UFSCar, 2000. p. 255-258.

GOMES, F. P. Curso de estatística experimental. 14. ed. Piracicaba: USP/ESALQ, 2000. 477p.

HACKETT, W.P. Phase change and intra clonal variability. HortScience, Alexandria, v. 18, n. 6, p. 840-844, 1983.

HARTMANN, H. T.; KESTER, D. E.; DAVIES JUNIOR, F. T.; GENEVE, R. L. Plant propagation: principles and practices. $7^{\text {th }}$ ed. New Jersey: Prentice Hall, 2002. 880p.

MAYER, N.A.; PEREIRA, F.M. Crescimento de três clones de umezeiro (Prunus mume Sieb. Et Zucc.) e pessegueiro cv. Okinawa (Prunus persica (L.) Batsch.) propagados por estacas herbáceas. Revista Brasileira de Fruticultura, Jaboticabal, v.26, n.1, p.113-116, 2004.

MELETTI, L.M.M. Propagação de frutíferas tropicais. Guaíba: Ed. Agropecuária, 2000. p.30-49.

PACHECO, R.G.; AGUILAR, M.A.G.; GOMES, A.R.S.; MARROCOS, P.C.L.; CHEPOTE, R.E.; SODRÉ, G.A. Estudo comparativo entre clones de cacau propagados por enxertia e estaquia no campo. In: ANNUAL MEETING OF THE INTERAMERICAN SOCIETY FOR TROPICAL HORTICULTURE, 49., 2003, Fortaleza. Resumos... Fortaleza: Embrapa Agroindústria Tropical, 2003. p. 90.

SAUCO, V.S.; MENINI, U.G.; TINDALL, H.D. Carambola cultivation. Rome: FAO, 1993.74p.

SCOTT, A. J.; KNOTT, M. A cluster analysis method for grouping means in the analysis of variance. Biometrics, Washington, v. 30, p. 507512,1974

ZIMMERMAN, R.H. Juvenility and flowering in wood plants: a review. HortScience, Alexandria, v.7, n. 5, p. 447-455, 1972. 